\title{
The influence of selected combinations of herbicides on the value of seeds of narrow leaved lupine (Lupinus angustifolius L.)
}

\section{Wpływ wybranych kombinacji ochrony herbicydowej na wartość siewną nasion łubinu wąskolistnego (Lupinus angustifolius L.)}

Katarzyna Panasiewicz*, Wiesław Koziara, Agnieszka Faligowska, Łukasz Sobiech, Monika Bartos-Spychała, Grzegorz Skrzypczak

\section{Summary}

The influence of herbicide protection on the value and vigor of seeds of narrow leaved lupine variety Zeus was investigated. The laboratory tests were carried out at the Department of Agronomy, Poznań University of Life Sciences. The seeds were derived from the field experiments conducted at the Agricultural Experimental Station Brody in 2012-2013. It was found that the active substances of herbicides significantly changed the seed quality of narrow leaved lupine variety Zeus. Moreover, the herbicide Wing P 462,5 EC significantly decreased germination capacity as compared to the control and other combinations. The active substances of examined herbicides did not influence on vigor of narrow leaved lupine variety Zeus.

Key words: herbicides; narrow leaved lupine (Lupinus angustifolius); sowing value; vigor

\section{Streszczenie}

W dwuletnim doświadczeniu laboratoryjnym prowadzonym w Laboratorium Nasiennictwa, Katedry Agronomii, Uniwersytetu Przyrodniczego w Poznaniu badano wpływ wybranych kombinacji ochrony herbicydowej na wartość siewną i wigor nasion łubinu wąskolistnego odmiany Zeus. Na podstawie uzyskanych wyników stwierdzono, że substancje czynne (s.cz.) badanych herbicydów istotnie modyfikowały wartość siewną nasion łubinu wąskolistnego odmiany Zeus. Najwyższy spadek zdolności kiełkowania w stosu nku do obiektu kontrolnego oraz pozostałych kombinacji odnotowano po aplikacji herbicydu Wing P 462,5 EC. W badaniach nie wykazano istotnego wpływu zastosowanych s.cz. herbicydów na wigor nasion łubinu wąskolistnego.

Słowa kluczowe: herbicydy; łubin wąskolistny (Lupinus angustifolius); wartość siewna; wigor

\author{
Uniwersytet Przyrodniczy w Poznaniu \\ Katedra Agronomii \\ Dojazd 11, 60-632 Poznań \\ *corresponding author: panas@up.poznan.pl
}




\section{Wstęp / Introduction}

Materiał siewny to podstawowy czynnik plonotwórczy. Stosowanie kwalifikowanego materiału siewnego uprawianych odmian, np. łubinu wąskolistnego (Lupinus angustifolius), jest najtańszym czynnikiem intensyfikującym technologię uprawy oraz ma istotny wpływ na produkcję nasion, jako surowca wykorzystywanego, np. w przemyśle paszowym (Prusiński 2007). Wymiana materiału siewnego w Polsce w ostatnich latach ulega stopniowemu wzrostowi, ale nadal w porównaniu do ,starych” krajów członkowskich Unii Europejskiej, poziom ten jest niezadawalający i średnio kształtuje się w granicach 15\%. Do głównych przyczyn braku zainteresowania przez praktykę rolniczą tym nośnikiem postępu biologicznego najczęściej zalicza się: rozdrobnienie gospodarstw, brak odpowiedniej wiedzy rolników, niską opłacalność produkcji, a także duży udział gleb słabych (Krasowicz 2008; Wicki 2008; Lisowska i wsp. 2013).

O jakości materiału siewnego decydują przede wszystkim uwarunkowania genetyczne oraz, jak wynika z wielu badań, również czynniki agrotechniczne (Sobiech i wsp. 1993; Faligowska i Szukała 2012; Krawczyńska i wsp. 2012; Panasiewicz i wsp. 2013; Vujaković i wsp. 2013).

Jednym z podstawowych zabiegów agrotechnicznych w uprawie roślin, w tym również łubinu, jest ochrona przed chwastami. Największe zagrożenie stanowią te gatunki, których rozwój trwa przez cały okres wegetacji, tj: Chenopodium album, Polygonum aviculare, $P$. persicaria, P. lapathifolium, Anthemis arvensis, Matricaria chamomilla, Tripleurospermum inodorum, Centaurea cyanus, Cirsium arvense, Sonchus arvensis, Artemisia vulgaris.

Odchwaszczanie plantacji łubinów za pomocą herbicydów nie jest łatwym zadaniem i wymaga od rolnika obszernej i aktualnej wiedzy na ten temat. Asortyment herbicydów zalecanych do stosowania w łubinach na przestrzeni ostatniej dekady został bardzo mocno ograniczony (Zalecenia 2014/2015), dlatego tak istotny jest właściwy dobór herbicydu oraz terminu jego aplikacji, aby był on selektywny dla roślin łubinu, a zarazem skutecznie niszczył występujące na plantacji gatunki chwastów (Rychcik 2005; Podleśny i wsp. 2006; Sekutowski i Badowski 2011; Krawczyk 2013). Stosowanie substancji czynnych (s.cz.) herbicydów w ochronie roślin może wpływać na właściwości fizjologiczne nasion, modyfikując przez to ich żywotność, a w konsekwencji wywoływać zmiany jakości siewnej (Grzesiuk 1973; Klimont i Dul 1998; Klimont i Osińska 2004). Stąd ważne zarówno dla nauki, jak i praktyki rolniczej jest poszukiwanie i poznanie skutecznych substancji chemicznych do ochrony plantacji łubinu wąskolistnego oraz ocena ich wpływu na wartość siewną nasion tego gatunku.

Celem podjętych badań było określenie parametrów wartości siewnej oraz wigoru nasion łubinu wąskolistnego w zależności od zastosowanych herbicydów.

\section{Materiały i metody / Materials and methods}

Doświadczenia laboratoryjne wykonano w Katedrze Agronomii Uniwersytetu Przyrodniczego w Poznaniu, na nasionach łubinu wąskolistnego odmiany Zeus, pozyskanych w latach 2012-2013 ze Stacji Zakładu Doświadczalno-Dydaktycznego Gorzyń, filia w Brodach. Badania wykonano jako jednoczynnikowe, w których uwzględniono nasiona uzyskane $\mathrm{z}$ obiektów kontrolnych (bez ochrony herbicydowej) oraz nasiona pochodzące z obiektów herbicydowych. Wykaz herbicydów zastosowanych w doświadczeniu polowym przedstawia tabela 1 .

Wilgotność nasion zebranych w roku 2012 wynosiła $10,4 \%$, a nasion uzyskanych w roku $2013-9,8 \%$. Zebrane nasiona przechowywano w warunkach kontrolowanych, tj. $4^{\circ} \mathrm{C}$, bez dostępu światła. W każdym roku po okresie 4-miesięcznego magazynowania dokonywano oceny jakości siewnej.

Tabela 1. Ochrona herbicydowa

Table 1. Herbicide protection

\begin{tabular}{|c|c|c|c|}
\hline $\begin{array}{l}\text { Nazwa preparatu } \\
\text { Treatment component }\end{array}$ & $\begin{array}{l}\text { Substancja czynna } \\
\text { Active substance }\end{array}$ & $\begin{array}{l}\text { Dawka } \\
\text { Dose } \\
{[1 / \text { ha }]} \\
\end{array}$ & $\begin{array}{l}\text { Termin stosowania } \\
\text { Date of application }\end{array}$ \\
\hline Legato $500 \mathrm{SC}$ & diflufenican $-500 \mathrm{~g}$ & 0,2 & $\begin{array}{l}\text { po siewie } \\
\text { after sowing }\end{array}$ \\
\hline Wing P 462,5 EC & $\begin{array}{c}\text { dimethenamid-P }-212,5 \mathrm{~g} \\
\text { pendimethalin }-250 \mathrm{~g}\end{array}$ & 3,0 & $\begin{array}{l}\text { po siewie } \\
\text { after sowing }\end{array}$ \\
\hline $\begin{array}{l}\text { Legato } 500 \mathrm{SC} \\
+ \\
\text { Betanal MaxxPro } 209 \text { OD }\end{array}$ & $\begin{array}{c}\text { diflufenican }-500 \mathrm{~g} \\
+ \\
\text { desmedipham }-47 \mathrm{~g} \\
\text { ethofumesate }-75 \mathrm{~g} \\
\text { lenacil }-27 \mathrm{~g} \\
\text { phenmedipham }-60 \mathrm{~g}\end{array}$ & $0,2+1,25$ & $\begin{array}{c}\text { po siewie } \\
\text { after sowing } \\
+ \\
\text { kolejne wschody chwastów } \\
\text { subsequent emergence } \\
\text { of weeds }\end{array}$ \\
\hline
\end{tabular}


Wartość siewną w każdym roku badań wyrażono za pomocą energii kiełkowania, zdolności kiełkowania oraz wigoru nasion zgodnie z wytycznymi ISTA (2011). Oznaczenie wigoru polegało na przeprowadzeniu 3 testów wigorowych. Test wzrostu siewki (test rulonowy) wykonany został w 4 powtórzeniach i polegał na umieszczeniu 25 nasion w rulonie bibuły filtracyjnej o średniej prędkości sączenia. Następnie arkusze bibuły nawilżone wodą dejonizowaną umieszczano $\mathrm{w}$ termostacie, $\mathrm{w}$ temperaturze $20^{\circ} \mathrm{C}$. Po zakończeniu procesu kiełkowania odpowiednio dla tego gatunku, odnotowano długość siewek normalnie kiełkujących $(\mathrm{cm})$ oraz średnią długość siewki na rulon. Test szybkości wzrostu siewki został wykonany po zakończeniu testu wzrostu siewki, wykorzystując siewki normalne z każdego rulonu (bez resztek nasion), które poddano suszeniu przez $24 \mathrm{~h} \mathrm{w}$ temperaturze $80^{\circ} \mathrm{C}$, a następnie określono masę pojedynczej siewki. Test elektroprzewodnictwa (pomiar konduktometrii eksudatów) przeprowadzono za pomocą konduktometru mikrokomputerowego CC-551 firmy Elektron.

Zważone $\mathrm{z}$ dokładnością do $0,01 \mathrm{~g}$ próby nasion (50 sztuk z każdego poletka) umieszczano w zlewkach o pojemności $400 \mathrm{~cm}^{3}$ i zalewano wodą dejonizowaną w objętości $250 \mathrm{~cm}^{3}$. Zlewki pozostawiano w termostacie w temperaturze $20^{\circ} \mathrm{C}$, a następnie po $24 \mathrm{~h}$ dokonywano pomiaru. Wyliczenie wartości indeksu wigoru wykonano na podstawie iloczynu średniej długości siewki i średniej zdolności kiełkowania. Ponadto oznaczono świeżą masę siewki oraz średnią długość korzonka.

Uzyskane wyniki poddano ocenie statystycznej, a najmniejszą istotną różnicę oszacowano testem t-Studenta na poziomie istotności $\alpha=0,05$.

\section{Wyniki i dyskusja / Results and discussion}

W przeprowadzonych badaniach na obiektach, w których stosowano herbicydy stwierdzono wzrost masy tysiąca nasion (MTN) w stosunku do obiektu kontrolnego, tj. bez ochrony herbicydowej, przy czym istotne zróżnicowanie w stosunku do tej kombinacji wykazano jedynie po użyciu mieszaniny herbicydów Legato $500 \mathrm{SC}+$ Betanal MaxxPro 209 OD. W literaturze naukowej brak jest jednoznacznej odpowiedzi na temat wpływu stosowanych herbicydów na tę cechę w przypadku roślin strączkowych. Często uważa się, że masa tysiąca nasion uwarunkowana jest przede wszystkim genetycznie. Sekutowski i Badowski (2011) nie wykazali istotnego wpływu stosowania herbicydów na masę tysiąca nasion grochu. Również Bujak i Frant (2009) nie stwierdzili istotnych różnic w masie tysiąca nasion soi po zastosowaniu różnych mieszanek herbicydowych. Z kolei Gugała i Zarzecka (2009) odnotowali wyraźny wzrost masy tysiąca nasion u grochu po zastosowaniu mieszaniny herbicydów Afalon Dyspersyjny 450 SC + Basagran 600 SL + Fusilade Forte 150 EC + adiuwant. Ci sami autorzy doszli do podobnych wniosków odnośnie wielkości masy tysiąca nasion, stosując mieszaninę herbicydów Afalon Dyspersyjny $450 \mathrm{SC}+$ Metron 700 SL + Fusilade Forte 150 EC w łubinie wąskolistnym (Gugała i Zarzecka 2012).

W badaniach własnych zastosowanie zróżnicowanej ochrony herbicydowej plantacji łubinu wąskolistnego przed chwastami powodowało istotne zmiany w przypadku energii kiełkowania oraz zdolności kiełkowania nasion tego gatunku (tab. 2). Analiza energii kiełkowania w zależności od zastosowanych kombinacji wykazała brak istotnych różnic w stosunku do obiektu kontrolnego (bez ochrony herbicydowej). Natomiast istotny spadek wartości tej cechy o 6 punktów procentowych stwierdzono pomiędzy obiektami, na których użyto środki: Legato 500 SC i Wing P 462,5 EC oraz Legato 500 SC + Betanal MaxxPro 209 OD. Z kolei przeprowadzona ocena zdolności kiełkowania wykazała, iż zastosowanie herbicydu Wing P 462,5 EC w porównaniu do pozostałych obiektów powodowało spadek o 6 punktów procentowych wartości tej cechy.

Tabela 2. Ocena wartości siewnej nasion łubinu wąskolistnego w zależności od zastosowanej ochrony herbicydowej

Table 2. Assessment of the sowing value of narrow leaved lupine depending on herbicide protection

\begin{tabular}{|c|c|c|c|c|c|c|c|c|c|}
\hline $\begin{array}{l}\text { Wariant } \\
\text { Treatment }\end{array}$ & 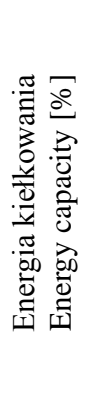 & 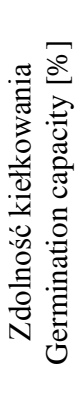 & 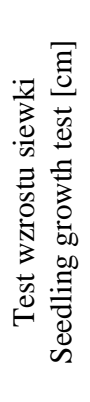 & 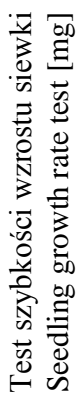 & 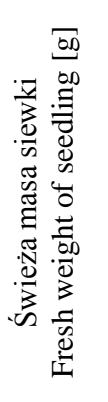 & 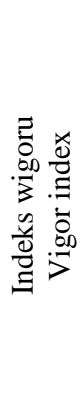 & 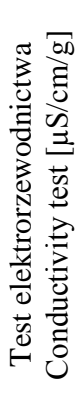 & 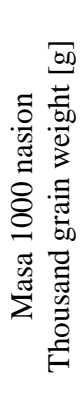 & 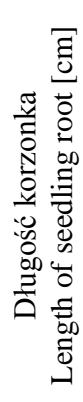 \\
\hline Legato $500 \mathrm{SC}$ & 95 & 96 & 10,4 & 35,7 & 0,795 & 998 & 20,4 & 132,1 & 9,97 \\
\hline Wing P 462,5 EC & 89 & 90 & 10,9 & 34,7 & 0,775 & 989 & 20,7 & 133,5 & 11,8 \\
\hline Legato 500 SC + Betanal MaxxPro 209 OD & 89 & 96 & 10,4 & 37,5 & 0,812 & 1000 & 20,5 & 138,2 & 12,0 \\
\hline Kontrola-Check & 92 & 96 & 11,1 & 34,8 & 0,792 & 1068 & 21,0 & 127,9 & 11,2 \\
\hline NIR $(0,05)-\operatorname{LSD}(0.05)$ & 3,5 & 2,0 & r.n. & r.n. & r.n. & r.n. & r.n. & 6,97 & 1,41 \\
\hline
\end{tabular}

r.n. - różnice nieistotne - not significant differences 
Ocena podstawowych parametrów wartości siewnej przeprowadzana jest w optymalnych warunkach dla wzrostu i rozwoju siewek, dlatego w badaniach oceniano również wigor nasion, co pozwala na szerszą analizę nie tylko z punktu widzenia ilości nasion kiełkujących, ale także jakości materiału siewnego przez uwzględnienie, np. parametrów wzrostowych siewek.

Zdaniem Bedforda i Matthewsa (1976), a także Grzysia i wsp. (1997), wigor to zjawisko złożone i może zależeć od wielu czynników, tj.: dojrzałości nasion, terminu zbioru, zróżnicowania topofizycznego, a nawet porażenia przez choroby i szkodniki. Dlatego wskazuje się, że ocenę wigoru powinno wykonywać się za pomocą wielu równolegle stosowanych metod (Grzyś i wsp. 1997; Kurasiak-Popowska i Szukała 2008).

Przeprowadzone badania własne, wskazują na brak zależności między zastosowanymi s.cz. herbicydów a wigorem nasion łubinu wąskolistnego. Można zauważyć jedynie pewne tendencje przejawiające się mniejszą średnią długością siewki łubinu (test wzrostu siewki) czy też niższą wartością indeksu wigoru.
Zastosowanie wybranych s.cz. herbicydów powodowało istotne zróżnicowanie średniej długości korzonka siewek. Spośród porównywanych kombinacji herbicydowych, najkrótsze korzonki odnotowano w przypadku użycia herbicydu Legato 500 SC.

\section{Wnioski / Conclusions}

1. Substancje czynne badanych herbicydów istotnie modyfikowały wartość siewną nasion łubinu wąskolistnego odmiany Zeus.

2. Spośród zastosowanych herbicydów, najniższą zdolność kiełkowania stwierdzono po aplikacji herbicydu Wing P 462,5 EC. Pozostałe herbicydy nie wywierały istotnego wpływu na wartość tej cechy.

3. Nie wykazano wpływu zastosowanych s.cz. herbicydów na wigor nasion łubinu wąskolistnego odmiany Zeus.

\section{Literatura / References}

Bedford L.W., Matthews S. 1976. The effect of seed age at harvest on the germinability and quality of heat-dried seed peas. Seed Science Technology 4: 275-286.

Bujak K., Frant M. 2009. Wpływ mieszanek herbicydów na plonowanie i zachwaszczenie pięciu odmian soi. Acta Agrophysica 13 (3): 601-613.

Faligowska A., Szukała J. 2012. Wpływ deszczowania i systemów uprawy roli na wigor i wartość siewną nasion łubinu żółtego. Science, Nature, Technologies/Nauka, Przyroda, Technologie 6 (2) \#26.

Grzesiuk S. 1973. Uboczny wpływ pestycydów na wartość biologiczną nasion. Postępy Nauk Rolniczych 3 (140): 45-60.

Grzyś E., Bielecki K., Demczuk A. 1997. Przydatność wybranych metod w określaniu wigoru nasion grochu i bobiku. Zeszyty Naukowe Akademii Rolniczej we Wrocławiu, Rolnictwo 308: 221-233.

Gugała M., Zarzecka K. 2009. Wpływ gęstości siewu i sposobów pielęgnacji na plonowanie grochu siewnego (Pisum sativum L.). Fragmenta Agronomica 26 (2): 64-71.

Gugała M., Zarzecka K. 2012. Wpływ metod uprawy roli i sposobów pielęgnacji na zachwaszczenie i plonowanie łubinu wąskolistnego odmiany Sonet. Fragmenta Agronomica 29 (1): 16-24.

International Rules for Seed Testing. ISTA. Międzynarodowe Przepisy Oceny Nasion. Polska Wersja Wydania 2011. Radzików.

Klimont K., Dul S. 1998. Ocena chwastobójczego działania preparatu Lintur 70 WG oraz jego wpływ na plon i wartość siewną ziarna jęczmienia jarego. Biuletyn Instytutu Hodowli i Aklimatyzacji Roślin 207: 93-98.

Klimont K., Osińska A. 2004. Wpływ herbicydów na wartość siewną i zawartość niektórych składników w ziarnie pszenicy ozimej, jęczmienia jarego i pszenżyta jarego. Biuletyn Instytutu Hodowli i Aklimatyzacji Roślin 233: 49-58.

Kurasiak-Popowska D., Szukała J. 2008. Wpływ systemów uprawy roli, dolistnego nawożenia mikroelementami i sposobów zbioru na kształtowanie zdolności kiełkowania i wigoru nasion łubinu żółtego odmiany Parys. Acta Scientiarum Polonorum Agricultura 7 (2): $51-67$.

Krasowicz S. 2008. Możliwości zwiększenia produkcji zbóż w Polsce w świetle badań agrotechnicznych i środowiskowych. Wieś Jutra 4: 69-70.

Krawczyk R. 2013. Regulacja zachwaszczenia upraw łubinu wąskolistnego (Lupinus angustifolius L.) i łubinu żółtego (Lupinus luteus L.) w zależności od ich zróżnicowania biologicznego oraz czynników agroekologicznych. Rozprawy Naukowe Instytutu Ochrony Roślin - PIB 28, 94 pp.

Krawczyńska M., Kołwzan B., Rybak J., Gediga K., Shcheglowa N. 2012. The influence of biopraparation on seed germination and growth. Polish Journal of Environmental Studies 21 (6): 1697-1702.

Lisowska M., Bombik A., Rymuza K., Ziemińska J., Wyrzykowska M. 2013. Stosowanie kwalifikowanego materiału siewnego w wybranych gospodarstwach rolnych w rejonie Polski środkowo-wschodniej. Fragmenta Agronomica 30 (2): 112-122.

Panasiewicz K., Koziara W., Sulewska H., Faligowska A., Krawczyk R. 2013. Sowing quality and vigor of narrow-leaved lupin (Lupinus angustifolius L.) cultivated in conventional system and in transition period to the organic farming. Journal of Research and Applications in Agricultural Engineering 58 (4): 91-94.

Podleśny J., Lenartowicz W., Księżak J. 1993. Przydatność niektórych herbicydów do zwalczania chwastów w zasiewach grochu. Fragmenta Agronomica 3: 177-188.

Prusiński J. 2007. Postęp biologiczny w tubinie (Lupinus sp.) - rys historyczny i stan aktualny. Zeszyty Problemowe Postępów Nauk Rolniczych 522: 23-37.

Rychcik B. 2005. Wpływ herbicydu i następstwa roślin na zachwaszczenie grochu pastewnego (Pisum sativum L.). [Effect of herbicide and crop sequence on weed infestation of pea field (Pisum sativum L.)]. Progress in Plant Protection/Postępy w Ochronie Roślin 45 (2): $1039-1042$. 
Sekutowski T., Badowski M. 2011. Wpływ zachwaszczenia oraz ochrony herbicydowej na plonowanie grochu siewnego (Pisum sativum L.). [Effect of weed infestation and herbicide protection on yielding of pea (Pisum sativum L.)]. Progress in Plant Protection/Postępy w Ochronie Roślin 51 (4): 1858-1863.

Sobiech S., Maciejewski T., Szukała J. 1993. Wpływ niektórych czynników agrotechnicznych na kiełkowanie nasion wyki jarej (Vicia sativa L.). Poznańskie Towarzystwo Przyjaciół Nauk 75: 55-61.

Vujaković M., Indić D., Jovičić D., Vuković S., Lončarević V., Gvozdenac S. 2013. Effects of insecticides on germination energy and germination of sugar beet seed depending on storage length. p. 235-239. In: Proceeding of 3rd International Conference on Food Technology and 25th National Conference on Process Technique and Energetics in Agriculture. Serbia, Vrnjačka Banja, April 21st-26th, 2013.

Wicki L. 2008. Wykorzystanie postępu odmianowego w produkcji zbóż w polskim rolnictwie. Roczniki Nauk Rolniczych, Seria G, 94 (2): 136-146.

Zalecenia ochrony roślin na lata 2014/2015. 2014. Instytut Ochrony Roślin - PIB, Poznań. 